\title{
Experimental model for transforaminal endoscopic spine ${ }^{1}$
}

Marcelo Campos Moraes Amato', Bruno César Aprile", Cézar Augusto de Oliveira"', Vinicius Marques Carneiro'v , Ricardo Santos de Oliveirav

'PhD, Amato - Instituto de Medicina Avançada, Sao Paulo-SP, Brazil. Conception and design of the study; acquisition, analysis and interpretation of data; technical procedures; manuscript preparation and writing; final approval.

"MD, Amato - Instituto de Medicina Avançada, Sao Paulo-SP, Brazil. Conception and design of the study, acquisition of data, technical procedures, critical revision.

I'MD, Amato - Instituto de Medicina Avançada, Sao Paulo-SP, Brazil. Technical procedures, acquisition of data.

IVMD, Division of Neurosurgery and Pediatric Neurosurgery, Department of Surgery and Anatomy, Hospital Universitário, Ribeirao Preto Medical School, Universidade de São Paulo (USP), Ribeirao Preto-SP, Brazil. Substantive scientific and intellectual contributions to the study, critical revision.

${ }^{\vee}$ PhD, Division of Neurosurgery and Pediatric Neurosurgery, Department of Surgery and Anatomy, Hospital Universitário, Ribeirao Preto Medical School, USP, Ribeirao Preto-SP, Brazil. Critical revision, final approval.

\section{Abstract}

Purpose: To validate the porcine spine as a model for learning and practicing transforaminal percutaneous endoscopic lumbar procedures (TF-PELP).

Methods: TF-PELP was performed in three porcine cadaver lumbar spine levels. Anatomical features of the current cadaver were compared to human and porcine spines. Performance and documentation of endoscopic procedures were described.

Results: This study shows that this representative animal model reflects anatomical characteristics of the human spine. Transforaminal approaches were successfully completed. Although lower disc heights make disc puncture more difficult, the outside-in technique is feasible and more useful to identify anatomical parameters and to practice different surgical steps and maneuvers.

Conclusion: This is an effective and representative model for learning and practicing this procedure. Difficulties of the procedure, as well as the differences compared to the human spine, were described.

Key words: Discectomy, Percutaneous. Endoscopy. Intervertebral Disc Displacement. Lumbar Vertebrae. Learning Curve. Models, Animal. 


\section{Introduction}

Spine endoscopy is used for a variety of surgical procedures such as discetomy, corpectomy, biopsy and tumor resection ${ }^{1,2}$. Transforaminal percutaneous endoscopic lumbar procedures (TF-PELP) are minimally invasive surgeries for disc herniations and foraminal stenosis. Although performed for more than twenty years, the continuous development of the surgical apparatus and indications for different types of disc herniations recently increased its popularity ${ }^{3,4}$.

Although the use of cadaver spines are considered gold standard for spine surgery education, the availability of human cadaver material is very limited in many regions ${ }^{5,6}$.

Porcine spines are frequently used as an alternative model to human specimens for in vivo and in vitro experiments involving spinal fusion and instrumentation techniques ${ }^{1,6-9}$. Although extensive biomechanical research has been done with animal spines, anatomical studies are still scarce ${ }^{6,9}$ and no previous study considered their use for this spine endoscopic technique.

The goal of this descriptive study was to determine whether the porcine spine can be a representative model for learning and practicing TF-PELP.

\section{- Methods}

All procedures performed in studies involving animals were in accordance with the ethical standards of the institution or practice at which the studies were conducted.

The fresh porcine cadaver used in this study was obtained according to ethics laws in experimental animal research. It was a 6 month-old Feral pig (Sus scrofa feral) weighting $50 \mathrm{~kg}$. All thoracic and abdominal viscera were removed, leaving the complete neurological axis. The length from the occiput to the end of the sacrum was of $84 \mathrm{~cm}$.

Antero-posterior (AP) and lateral fluoroscopic images were obtained from cervical, thoracic and lumbar spine of the porcine model. Anatomical dimensions of the lumbar vertebrae were measured and compared to the average measures of human and porcine cadavers studied by other authors ${ }^{6,9-12}$.

Relevant anatomical features of the lumbar vertebrae of the porcine spine was described. As well as performance and documentation of several transforaminal endoscopic procedures in order to determine whether the porcine lumbar spine can be a representative model for the practice of such procedures.

TF-PELP was performed in three lumbar spine levels (L3L4, L4L5 and L5L6) on a single porcine cadaver,

This procedure entails the use of a thin tubular device that contains the optical system and working channel, that is introduced through a stab incision. After positioning and marking, a dorsal lateral needle puncture is targeted to the disc, a wire is then inserted inside the needle to guide the obturator through the disc. The working sleeve is passed over the obturator, which is removed to insert the endoscope. A mono portal technique is standard and surgery is performed under constant saline irrigation ${ }^{13-16}$. After the transforaminal approach under fluoroscopic control and endoscopic visualization, anatomical structures were identified and specific maneuvers were attempted.

\section{- Results}

The porcine spine had 7 cervical, 15 thoracic, and 6 lumbar vertebrae, while the human spines have, respectively, 7, 12, and 5 . 
Tables 1 and 2 show anatomical dimensions of the current porcine lumbar spine, as well as the dimensions of human and porcine lumbar spines from other studies.

Relevant considerations of the procedures realized on the porcine cadaver and comparison to actual transforaminal endoscopic surgeries are described below. The surgical steps required real-time anteroposterior (AP) and/or lateral view in the C-Arm.

Table 1 - Average CT measurement of the Busscher et al. ${ }^{6}$ study on the porcine and human lumbar vertebrae, Dath et al. ${ }^{9}$ anatomical measurements of the porcine lumbar vertebrae, Panjabi et al. ${ }^{11}$ human vertebrae dimensions and the current porcine model fluoroscopic measurement of Vertebral Body Height anterior (VBHa), Vertebral Body Height central (VBHc), Vertebral Body Height posterior (VBHp).

\begin{tabular}{|c|c|c|c|c|c|c|c|c|c|c|c|c|}
\hline & \multirow{3}{*}{$\begin{array}{l}\text { VBH } \\
\text { Human } \\
\text { Panjabi } \\
\text { et al }\end{array}$} & \multicolumn{4}{|c|}{ VBHa } & \multicolumn{3}{|c|}{ VBHC } & \multicolumn{4}{|c|}{ VBHp } \\
\hline & & \multirow{2}{*}{$\begin{array}{l}\text { Human } \\
\text { Busscher } \\
\text { et al }\end{array}$} & \multicolumn{3}{|c|}{ Porcine } & \multirow{2}{*}{$\begin{array}{l}\text { Human } \\
\text { Busscher } \\
\text { et al }\end{array}$} & \multicolumn{2}{|c|}{ Porcine } & \multirow{2}{*}{$\begin{array}{l}\text { Human } \\
\text { Busscher } \\
\text { et al }\end{array}$} & \multicolumn{3}{|c|}{ Porcine } \\
\hline & & & $\begin{array}{l}\text { Busscher } \\
\text { et al }\end{array}$ & $\begin{array}{l}\text { Dath } \\
\text { et al }\end{array}$ & $\begin{array}{l}\text { VBHa } \\
\text { model }\end{array}$ & & $\begin{array}{l}\text { Buscher } \\
\text { et al }\end{array}$ & $\begin{array}{l}\text { VBHc } \\
\text { model }\end{array}$ & & $\begin{array}{l}\text { Buscher } \\
\text { et al }\end{array}$ & $\begin{array}{l}\text { Dath } \\
\text { et al }\end{array}$ & $\begin{array}{l}\text { VBHp } \\
\text { model }\end{array}$ \\
\hline L1 & $\begin{array}{l}23.8 \\
(1.0)\end{array}$ & $\begin{array}{l}25.5 \\
(2.5)\end{array}$ & $\begin{array}{l}23.6 \\
(3.3)\end{array}$ & $\begin{array}{l}33.7 \\
(0.4)\end{array}$ & 30.8 & $\begin{array}{l}24.5 \\
(4.8)\end{array}$ & $\begin{array}{l}22.6 \\
(2.8)\end{array}$ & 29.8 & $\begin{array}{l}28.5 \\
(2.5)\end{array}$ & $\begin{array}{l}23.7 \\
(2.3)\end{array}$ & $\begin{array}{l}34.9 \\
(0.5)\end{array}$ & 32.3 \\
\hline L2 & $\begin{array}{l}24.3 \\
(0.9)\end{array}$ & $\begin{array}{l}27.3 \\
(2.8)\end{array}$ & $\begin{array}{l}23.8 \\
(3.3)\end{array}$ & $\begin{array}{l}34.6 \\
(0.5)\end{array}$ & 30.3 & $\begin{array}{l}24.7 \\
(3.6)\end{array}$ & $\begin{array}{l}23.4 \\
(2.7)\end{array}$ & 29.3 & $\begin{array}{l}29.8 \\
(1.2)\end{array}$ & $\begin{array}{l}24.0 \\
(2.9)\end{array}$ & $\begin{array}{l}35.8 \\
(0.5)\end{array}$ & 31.1 \\
\hline L3 & $\begin{array}{l}23.8 \\
(1.1)\end{array}$ & $\begin{array}{l}28.7 \\
(1.9)\end{array}$ & $\begin{array}{l}24.7 \\
(3.1)\end{array}$ & $\begin{array}{l}35.3 \\
(0.4)\end{array}$ & 31.0 & $\begin{array}{l}25.5 \\
(0.8)\end{array}$ & $\begin{array}{l}23.4 \\
(2.9)\end{array}$ & 29.9 & $\begin{array}{l}29.8 \\
(1.0)\end{array}$ & $\begin{array}{l}24.4 \\
(2.4)\end{array}$ & $\begin{array}{l}36.6 \\
(0.5)\end{array}$ & 32.3 \\
\hline L4 & $\begin{array}{l}24.1 \\
(1.1)\end{array}$ & $\begin{array}{l}27.8 \\
(2.4)\end{array}$ & $\begin{array}{l}24.8 \\
(3.5)\end{array}$ & $\begin{array}{l}36.1 \\
(0.4)\end{array}$ & 31.9 & $\begin{array}{l}24.1 \\
(3.4)\end{array}$ & $\begin{array}{l}24.0 \\
(3.2)\end{array}$ & 30.4 & $\begin{array}{l}28.0 \\
(2.1)\end{array}$ & $\begin{array}{l}24.9 \\
(3.0)\end{array}$ & $\begin{array}{l}37.2 \\
(0.4)\end{array}$ & 32.2 \\
\hline L5 & $\begin{array}{l}22.9 \\
(0.9)\end{array}$ & $\begin{array}{l}29.5 \\
(1.4)\end{array}$ & $\begin{array}{l}24.7 \\
(3.7)\end{array}$ & $\begin{array}{l}36.0 \\
(0.4)\end{array}$ & 30.6 & $\begin{array}{l}25.3 \\
(1.8)\end{array}$ & $\begin{array}{l}23.9 \\
(3.7)\end{array}$ & 29.5 & $\begin{array}{l}24.9 \\
(3.8)\end{array}$ & $\begin{array}{l}25.0 \\
(3.0)\end{array}$ & $\begin{array}{l}36.3 \\
(0.6)\end{array}$ & 30.3 \\
\hline L6 & & & $\begin{array}{l}23.9 \\
(3.2)\end{array}$ & $\begin{array}{l}34.4 \\
(0.5)\end{array}$ & 30.7 & & $\begin{array}{l}23.0 \\
(3.7)\end{array}$ & 28.6 & & $\begin{array}{l}23.4 \\
(3.3)\end{array}$ & $\begin{array}{l}33.0 \\
(0.7)\end{array}$ & 30.0 \\
\hline
\end{tabular}


Table 2 - Average CT measurement of the Busscher et al. ${ }^{6}$ study on the porcine lumbar Interverterbral Disc Height (IDH), MRI measurement of human IDH from the Abdollah et al. ${ }^{12}$ study and current porcine model fluoroscopic measurement of important parameters for an TF-PELP: Intervertebral Disc Height central (IDHC), Intervertebral Disc Height medial pedicular line (IDHmp), Intervertebral Disc Height posterior (IDHp), Pedicle Height (PedH), Intervertebral Foramen Height (IVFH) and Intervertebral Foramen Depth (IVFD). The IDHc was measured in the AP as well as in the lateral fluoroscopic view. IDHmp was an average of left and right measurements. PedH and IVFH were measured in the AP view and IVFD in the lateral view. The data form the Abdollah study considered measurement of disc height using a combination of Dabbs and Hurxthals of 43 human spine MRIs with disc in different grades of degeneration ${ }^{6}$.

\begin{tabular}{|c|c|c|c|c|c|c|c|c|c|c|c|}
\hline & $\begin{array}{c}\text { IDH } \\
\text { (Buscher } \\
\text { et al) }\end{array}$ & $\begin{array}{l}\text { Human } \\
\text { IDH } \\
\text { (Abdollah } \\
\text { et al) }\end{array}$ & $\begin{array}{l}\text { IDHc } \\
\text { model } \\
\text { AP }\end{array}$ & $\begin{array}{l}\text { IDHmp } \\
\text { model } \\
\text { AP }\end{array}$ & $\begin{array}{l}\text { IDHc } \\
\text { model } \\
\text { lateral }\end{array}$ & $\begin{array}{l}\text { IDHp } \\
\text { model } \\
\text { lateral }\end{array}$ & $\begin{array}{l}\text { PedH } \\
\text { left }\end{array}$ & $\begin{array}{l}\text { PedH } \\
\text { right }\end{array}$ & $\begin{array}{l}\text { IVFH } \\
\text { left }\end{array}$ & $\begin{array}{l}\text { IVFH } \\
\text { right }\end{array}$ & IVFD \\
\hline L1L2 & $2.7(0.5)$ & & 4.1 & 2.6 & 4.0 & 2.8 & 12.3 & 13.2 & 19.8 & 17.1 & 9.9 \\
\hline L2L3 & $2.9(0.4)$ & & 4.0 & 3.1 & 4.3 & 2.5 & 15.9 & 15.5 & 16.9 & 16.2 & 10.0 \\
\hline L3L4 & $2.6(0.8)$ & & 4.4 & 3.1 & 4.9 & 2.1 & 17.2 & 16.1 & 15.8 & 15.9 & 8.9 \\
\hline L4L5 & $2.7(0.9)$ & $10.5(2.0)$ & 5.4 & 3.3 & 5.0 & 2.5 & 19.7 & 15.2 & 14.6 & 19.2 & 8.2 \\
\hline $\begin{array}{l}\text { L5L6 } \\
\text { (L5S1) }\end{array}$ & $3.0(0.8)$ & $9.8(2.4)$ & 4.9 & 3.2 & 4.5 & 2.0 & 18.4 & 18.0 & 12.4 & 13.3 & 7.8 \\
\hline L6S1 & $2.9(0.9)$ & & 3.6 & 2.5 & 3.4 & 3.3 & 16.6 & 17.9 & NA & NA & 6.8 \\
\hline
\end{tabular}

\section{First step}

Positioning and marking (Figure $1 \mathrm{~A}-\mathrm{E}$ )

A guide wire was positioned over the spinous process line in the anteroposterior (AP) view to allow drawing a line over the dorsum of the porcine model (Figure 1A). Then the guide wire was positioned across the middle disc line to draw a perpendicular line over the model (Figure 1B). In the lateral view, the guide wire was positioned over the spinous process line
(Figure 1C) and the facets line (Figure 1D) to draw security lines over the postero-lateral aspect of the dorsum. The last two lines are used to prevent inserting the needle too anterior. The area between those lines can be used to perform a far-lateral approach to lumbar spine, not attempted in this study. The entry point selected for the TF-PELP in this model was between the spinous process line and the facets line, $12 \mathrm{~cm}$ lateral to the medial line (Figure 1E). 


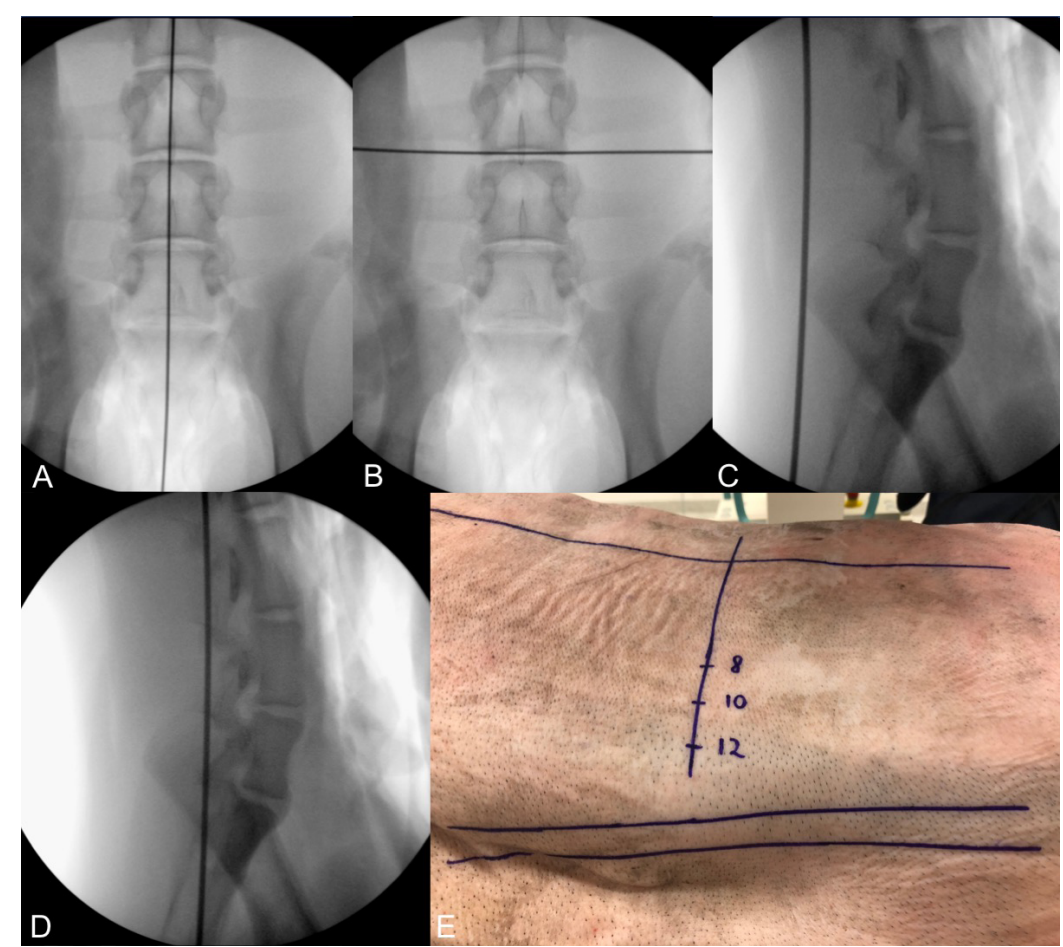

Figure 1 - A,B. AP Fluoroscopic views for midline and disc line marking. C,D. Lateral views for spinous process and facets lines marking. E. Corresponding marks on the model dorsum.

\section{Needle insertion into the disc (Figure 2A-B)}

The target point used for needle insertion was the same as used for humans: medial pedicular line in the AP view and posterior vertebral or posterior disc line in the lateral view.

The insertion of a $18 \mathrm{G}$ needle into the disc was possible in L3L4 and L4L5, although very difficult due to lower disc heights in the porcine lumbar spine when compared to human discs (Table 1). In L5L6, disc puncture was not possible, but it did not prevent the surgeon to continue the TF-PELP. For these steps it is recommended to start on real-time $A P$ view and shift to lateral view as the disc or any other structure is felt, always preventing that the needle goes further than the medial pedicular line. If the trajectory must be corrected, shift back to AP view to start over; after disc puncture, the following steps can be performed on the lateral view. In the discs where the needle was inserted, it was possible to inject a small amount of methylene blue, not greater than $1 \mathrm{ml}$.

Guide wire, obturator, working-sheet and endoscope (Figure 2C-F)

The guide wire is than inserted inside the cannulated needle without further difficulties in L3L4 and L4L5. Except for the L5L6, where the needle stayed in the posterior aspect of the vertebral body, adjacent to the disc, the guide-wire was forced inside the bone to allow the next steps of the procedure. The following steps did not create further difficulties that could be considered differently than human surgeries. After removal of the needle, an obturator was introduced along the guide wire and its position was confirmed (Figure 2D). The guide-wire was removed, and a bevelended working sheath was introduced along the obturator and placed adjacent to the disc (Figure 2E). After removal of the working-sheet (Figure 2F) and insertion of the endoscope, the first step of the procedure is complete. 


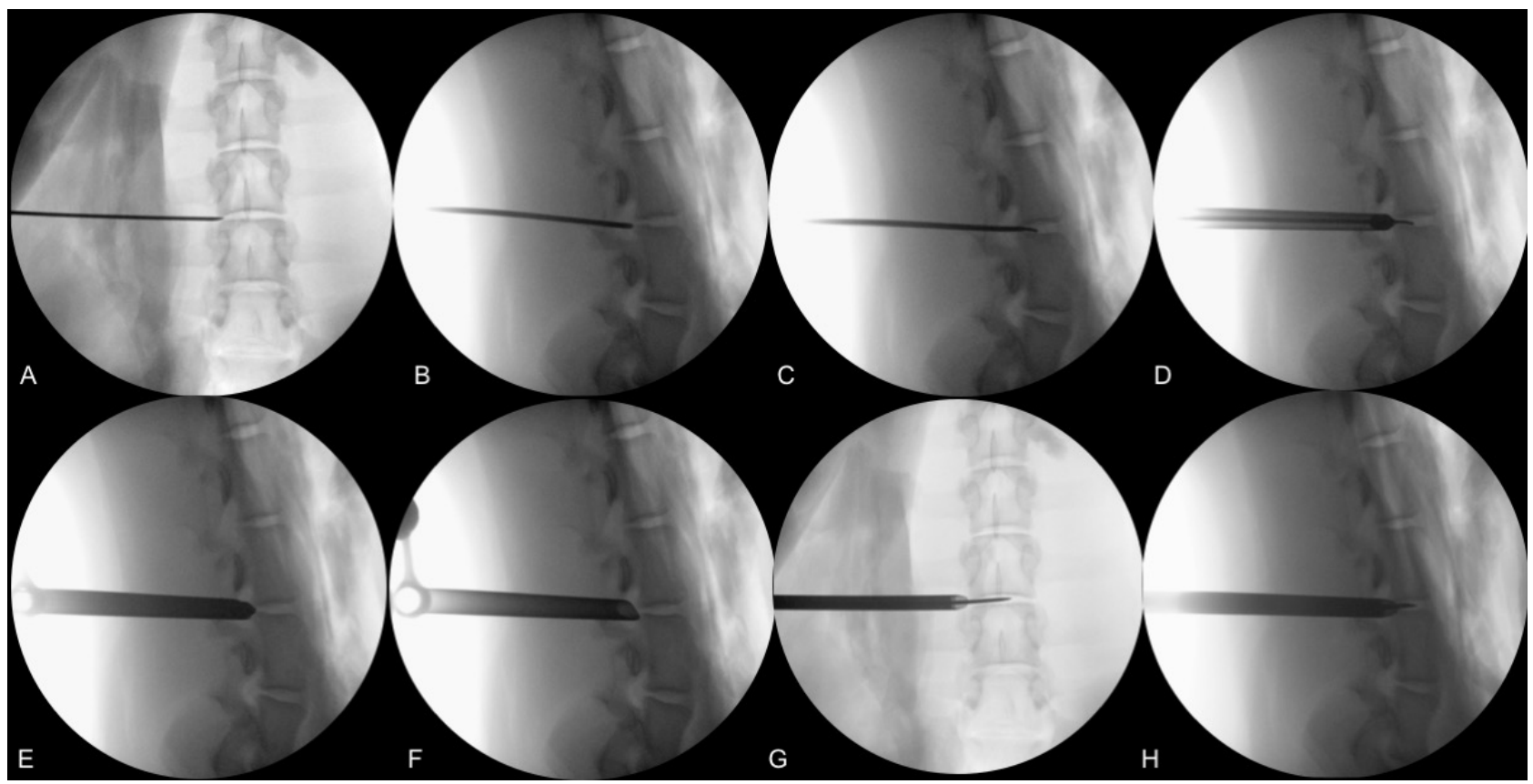

Figure 2 - Fluoroscopic views of the procedure. Insertion of the needle (A, B), guide wire. (C), obturator. (D), working canula $(\mathbf{E})$, and withdrawal of the obturator $(\mathbf{F})$. Documentation of instruments inside the disc at the end of the procedure on AP $(\mathbf{G})$ and lateral $(\mathbf{H})$ views.

\section{Second step}

\section{Endoscopic view and anatomic identification}

In this second step, fluoroscopy is only used to check position of the instruments and verify anatomic parameters. After insertion of the endoscope and cleaning of the operatory field with radiofrequency ablation, it was possible to identify the same structures as in human procedures: the blue stained disc, the superior articular process (SAP) of the inferior vertebrae and the emerging nerve root (Figure 3A). Additionally it was possible to identify the inferior articular process (IAP) of the superior vertebrae and its extension with the cranial laminae.
SAP drilling and exposition of the dural sac

Using an oval cutting burr and a Kerrison punch, it was possible to partially drill out the SAP and IAP to expose the descending root within the dural sac (Figure $3 \mathrm{~B}-\mathrm{C}$ ).

\section{Discectomy and emerging root dissection}

As with the insertion of the needle into the porcine lumbar disc, the introduction of instruments inside the disc was also very difficult. However, the identification of the discs was very clear, and it was possible to introduce a chisel inside (Figure 2F-G). At the end of the procedure it was possible to identify both emerging and descending roots with the annulus fibrosus in between along with a significant amount of fat (Figure 3D). 


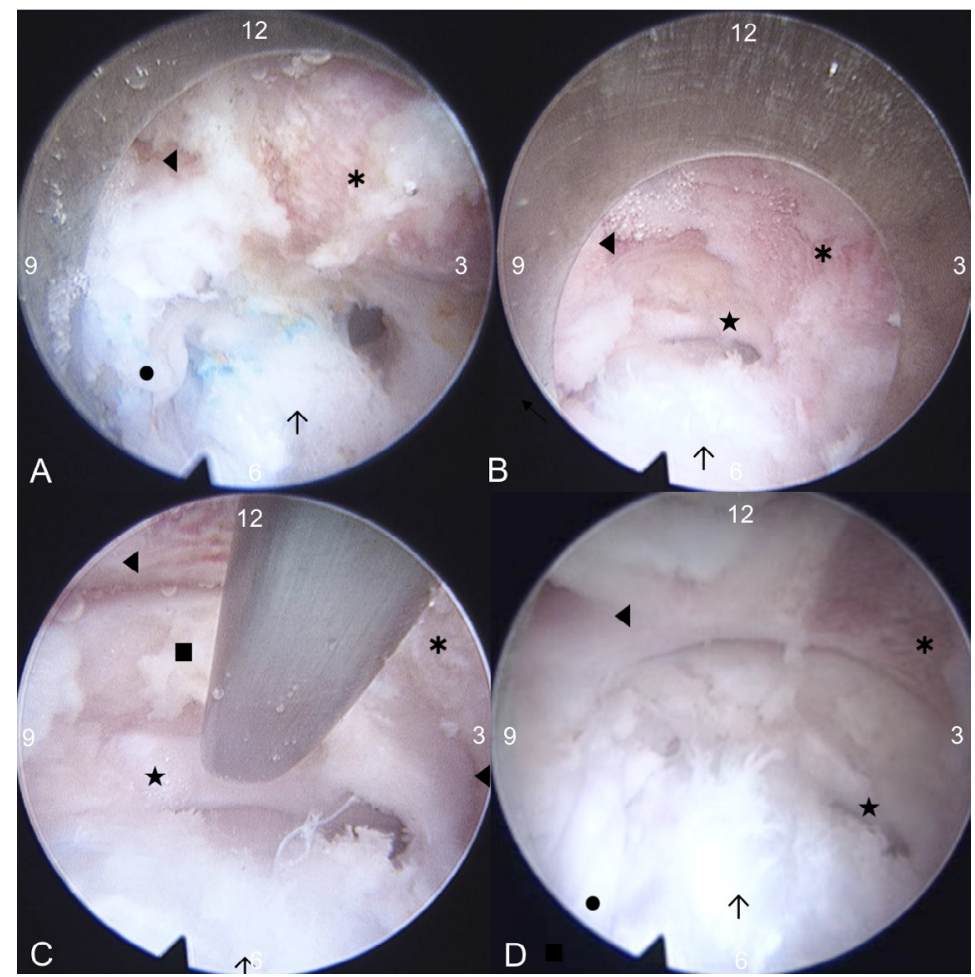

Figure 3 - Endoscopic views of the procedure. 12 o'clock is midline (right side), 3 is caudal, 6 is lateral (left side) and 9 is cranial. A) 4 inferior laminae and articular process $*$ superior articular process; $\bullet$ emerging nerve root; $\uparrow$ annulus fibrosus (blue stained); B) after drilling the SAP and IAP: 4 inferior laminae and articular process $*$ superior articular process; $\uparrow$ annulus fibrosus (blue stained); $\star$ dural sac; C) closer midline view: $\downarrow$ inferior laminae and articular process $*$ superior articular process; $\uparrow$ annulus fibrosus (blue stained) $\star$ dural sac; yellow ligament; D) after slight rotation of the endoscope, a closer superior view, cranial is at 11 and midline is at 2 o'clock: $\varangle$ inferior laminae and articular process $*$ superior articular process; $\uparrow$ annulus fibrosus (blue stained); $\star$ dural sac; • emerging nerve root.

\section{- Discussion}

Although endoscopic spinal surgery is becoming more popular, the lack of proper training often leads to poor clinical results, discouraging the use of this undoubtedly effective technique.

As previously described, TF-PELP has a very steep learning curve. Lee and Lee ${ }^{17}$ show a significant reduction in operating time after treating their first 17 patients, additionally Kafadar et al. ${ }^{18}$ show a significant higher number of reoperations in their first 8 months experience with this technique. Therefore, along with proper indication of the procedure, education of the surgeon is essential.
Due to limited availability of human cadaver spines, particularly in Brazil, surgeons are being forced to travel abroad to participate in available cadaver hand-on courses to learn or improve such techniques, or may even be skipping this important step of the learning process.

As well as several other anatomical studies of the porcine spine, this study shows that this representative animal model reflects anatomical characteristics of the human spine ${ }^{6}$. Busscher et al. ${ }^{6}$ used 6 four monthold domestic Landrace pigs with an average weight of $40 \mathrm{~kg}$ for a fine anatomical study based on CT scans. Dath et al. ${ }^{9}$ used 18 to 24 month hybrid pigs weighting from 60 to 
$80 \mathrm{~kg}$, and they macroscopically dissected the vertebrae to perform their measurements. Although different methods were used, their studies considered larger samples and detailed anatomical measurements that were important to evaluate whether our study would be possible to replicate. The current model is bigger than those used by Busscher et $a .^{6}$ and smaller than those used by Dath et $a l .{ }^{9}$, however the main characteristics and proportions are maintained. It is interesting to note that the IVFH has the same behavior as in humans, higher in the upper lumbar spine and increasingly smaller as going caudally. Although the IDH is a bit greater when compared to Busscher samples, it is still much smaller when compared to humans. The human spine demands relatively larger caudal vertebral bodies to balance the higher longitudinal loads, in opposition to the quadruped spine. Also the greater range of motion of the lumbar human spine demands adaptable joints. These are probably some of the explanations for the smaller intervertebral discs heights observed in the porcine, which can be up to four times smaller than human disc heights in the lumbar region as shown in Table 2 and described by Busscher et al. ${ }^{6}$.

Additionally the lumbar Intervertebral foramen as height as 12.4 to $19.8 \mathrm{~mm}$ allow enough space for the endoscope introduction. The IVFD however (6.8 to $10.0 \mathrm{~mm})$ limits the introduction of the endoscope inside the foramen, and with the correct use of its denomination, the transforaminal approach. The lower disc heights also make the disc puncture more difficult. However, training to start the procedure outside the foramen, extraforaminal, is more useful to identify the anatomical parameters and to practice different surgical steps and maneuvers such as foraminoplasty, outside-in discectomy, emerging root and dural sac dissection, upward and downward exploration for possible disc fragments migrations.

\section{Conclusions}

The porcine spine is an effective, easily reproducible and representative model for learning and practicing transforaminal percutaneous endoscopic lumbar procedures. Although the described anatomical differences should be known, they do not interfere in learning and practicing all steps of TF-PELP in the porcine model.

\section{References}

1. Bozkus H, Crawford NR, Chamberlain RH, Valenzuela TD, Espinoza A, Yüksel Z, Dickman CA. Comparative anatomy of the porcine and human thoracic spines with reference to thoracoscopic surgical techniques. Surg Endosc. 2005;19(12):1652-65. doi: 10.1007/ s00464-005-0159-9.

2. Caputy A, Starr J, Riedel C. Video-assisted endoscopic spinal surgery: thoracoscopic discectomy. Acta Neurochir (Wien). 1995;134(3-4):196-9. PMID: 8748781.

3. Nie H, Zeng J, Song Y, Chen G, Wang X, Li Z, Jiang $H$, Kong $Q$. Percutaneous endoscopic lumbar discectomy for L5-S1 disc herniation via an interlaminar approach versus a transforaminal approach: A prospective randomized controlled study with 2-year follow up. Spine (Phila Pa 1976). 2016;41 Suppl 19:B30-7. doi: 10.1097/ BRS.0000000000001810.

4. Choi KC, Park CK. Percutaneous endoscopic lumbar discectomy for L5-S1 disc herniation: consideration of the relation between the iliac crest and L5-S1 disc. Pain Physician. 2016;19(2):E301-8. PMID: 26815257.

5. Olinger A, Pistorius G, Lindemann W, Vollmar B, Hildebrandt $U$, Menger MD. Effectiveness of a hands-on training course for laparoscopic spine surgery in a porcine model. Surg Endosc. 1999;13(2):118-22. PMID: 9918610.

6. Busscher I, Ploegmakers JJ, Verkerke GJ, Veldhuizen AG. Comparative anatomical dimensions of the complete human and porcine spine. Eur Spine J. 2010;19(7):110414. doi: 10.1007/s00586-010-1326-9.

7. McLain RF, Yerby SA, Moseley TA. Comparative morphometry of L4 vertebrae: 
comparison of large animal models for the human lumbar spine. Spine (Phila Pa 1976). 2002;27(8):E200-6. PMID: 11935119.

8. Goel VK, Panjabi MM, Patwardhan AG, Dooris AP, Serhan $H$, American Society for Testing and Materials. Test protocols for evaluation of spinal implants. J Bone Joint Surg Am. 2006;88 Suppl 2:103-9. doi: 10.2106/JBJS.E.01363.

9. Dath R, Ebinesan AD, Porter KM, Miles AW. Anatomical measurements of porcine lumbar vertebrae. Clin Biomech (Bristol, Avon). 2007;22(5):607-13. doi: 10.1016/j. clinbiomech.2007.01.014.

10.Kumar N, Kukreti S, Ishaque M, Mulholland R. Anatomy of deer spine and its comparison to the human spine. Anat Rec. 2000;260(2):189-203. PMID: 10993955.

11.Panjabi MM, Goel V, Oxland T, Takata K, Duranceau J, Krag M, Price M. Human lumbar vertebrae. Quantitative threedimensional anatomy. Spine (Phila Pa 1976). 1992;17(3):299-306. PMID: 1566168.

12.Abdollah V, Parent EC, Battié MC. Reliability and validity of lumbar disc height quantification methods using magnetic resonance images. Biomed Tech (Berl). 2018 doi: 10.1515/bmt-2017-0086.

13.Ahn $\mathrm{Y}$, Kim $\mathrm{CH}$, Lee $\mathrm{JH}$, Lee $\mathrm{SH}$, Kim JS. Radiation exposure to the surgeon during percutaneous endoscopic lumbar discectomy: A prospective study. Spine (Phila Pa 1976). 2013;38(7):617-25. doi: 10.1097/BRS.0b013e318275ca58.

14.Yeung AT, Tsou PM. Posterolateral endoscopic excision for lumbar disc herniation: Surgical technique, outcome, and complications in 307 consecutive cases. Spine (Phila Pa 1976). 2002;27(7):722-31. PMID: 11923665.

15.Ahn Y, Lee SH, Park WM, Lee HY, Shin SW, Kang HY. Percutaneous endoscopic lumbar discectomy for recurrent disc herniation: Surgical technique, outcome, and prognostic factors of 43 consecutive cases. Spine (Phila $\mathrm{Pa}$ 1976). 2004;29(16):E326-32. PMID: 15303041.

16. Birkenmaier C, Komp M, Leu HF, Wegener B, Ruetten $S$. The current state of endoscopic disc surgery: Review of controlled studies comparing full-endoscopic procedures for disc herniations to standard procedures. Pain Physician. 2013;16(4):335-44. PMID: 23877449.

17.Kafadar A, Kahraman S, Akbörü $M$. Percutaneous endoscopic transforaminal lumbar discectomy: a critical appraisal. Minim Invasive Neurosurg. 2006;49(2):749. doi: $10.1055 / \mathrm{s}-2006-932184$.

18. Lee DY, Lee SH. Learning curve for percutaneous endoscopic lumbar discectomy. Neurol Med Chir (Tokyo). 2008;48(9):383-8. PMID: 18812679.

\section{Acknowledgements}

To Dr. Salvador Amato and Mr. Timothy Coyne for their technical assistance.

\section{Correspondence:}

Marcelo Campos Moraes Amato

Avenida Brasil, 2283

01431001 São Paulo - SP Brasil

Tels.: (55 11)5053-2222 / 99937-2565

amato@neurocirurgia.com

Received: Aug 03, 2018

Review: Oct 08, 2018

Accepted: Nov 05, 2018
Conflict of interest: none

Financial source: none

\footnotetext{
${ }^{1}$ Research performed at Division of Neurosurgery and Pediatric Neurosurgery, Department of Surgery and Anatomy, Hospital Universitário, Ribeirao Preto Medical School, Universidade de São Paulo (USP), Ribeirao Preto-SP, Brazil.
} 